SISTEMA
ELETRÔNICO
DE REVISTAS
SER I UFPR

\title{
Avaliação da Qualidade Ambiental Urbana (QAU) aplicada antes e depois do processo de regularização fundiária: estudo de caso Vila Terra Santa - Curitiba/PR
}

\section{Evaluation of Urban Environmental Quality (UEQ) Applied Before and After Land Regularization Process: A Case Study of Vila Terra Santa - Curitiba/PR}

\author{
Gabriela do Vale SILVA ${ }^{1 *}$, Tamara Simone van KAICK ${ }^{1}$, Stella Maris da Cruz BEZERRA ${ }^{1}$ \\ ${ }^{1}$ Programa de Pós-Graduação em Ciência e Tecnologia Ambiental (PPGCTA), Universidade Tecnológica Federal do Paraná (UTFPR), Curitiba, \\ PR, Brasil. \\ ${ }^{*}$ E-mail de contato: gabi_vale@hotmail.com
}

Artigo recebido em 18 de maio de 2016, versão final aceita em 8 de novembro de 2017.

\begin{abstract}
RESUMO: Este trabalho teve como objetivo avaliar a Qualidade Ambiental Urbana (QAU), em um processo de regularização fundiária em ocupação irregular localizada em Área de Preservação Permanente (APP). Para verificar as mudanças ocorridas no processo de regularização, foi analisado um estudo de caso: Vila Terra Santa, em Curitiba/PR. Foram levantados dados primários e secundários em dois períodos distintos, sendo o período I anterior (ano 2000-2007) e o II posterior (ano 2008-2013) à regularização fundiária. A metodologia de análise da Qualidade Ambiental Urbana foi adaptada para esta pesquisa e consistiu em oito categorias de análise, as quais contém 34 variáveis e 43 indicadores voltados para aspectos socioambientais e de infraestrutura. Também foi desenvolvido um sistema de Índice de Qualidade Ambiental Urbana (IQAU) parcial, por categoria de análise. Para melhor avaliação, foram atribuídos valores para cada variável e para cada categoria, por fim, para o IQAU final, foram indicados classes de qualidade de $\mathrm{A}$ a $\mathrm{E}$, estando $\mathrm{A}$ em nível de qualidade extremamente satisfatório e $\mathrm{E}$ muito insatisfatório, tendo outras três classes entre esses extremos. Com os resultados foi possível identificar que houve melhoria em seis categorias de análise após o processo de regularização, que ficaram evidenciados em $65 \%$ das 34 variáveis avaliadas, comparando os dois períodos. O IQAU final apontou um índice de 40,15 no período I, alocado na classe D que é o nível de qualidade insatisfatório. No período II, o índice foi de 72,98 , classificando a qualidade ambiental da Vila Terra Santa em B, muito satisfatória. Os resultados dos índices no QAU demonstraram a viabilidade de aplicação dos mesmos como ferramentas de apoio à tomada de decisão para os gestores.
\end{abstract}


Palavras-chave: ocupação irregular; índice de qualidade ambiental urbana; gestão ambiental.

ABSTRACT: This study aimed to evaluate Urban Environmental Quality - UEQ in a land going through a regularization process in irregular settlements located in a Permanent Preservation Area - APP. In order to check the changes in the regularization process, a case study was analyzed: the one of Vila Terra Santa in Curitiba / PR. Primary and secondary data were collected in two different periods of land regularization, the first set in the period between the years of 2000-2007, before the process, and the second one in the period between the years of 2008-2013, after the process. The methodology of Urban Environmental Quality was adapted for this study and consisted of eight categories of analysis with 34 variables and 43 indicators, focused on social and environmental aspects and infrastructure. It was also developed an Urban Environmental Quality Index System - UEQI by category of analysis. For a better evaluation, the values assigned to each variable for each category and, finally, to the final UEQI, were indicated in a system of quality grades from A to E, with A being a extremely satisfactory quality level, and E a very unsatisfactory level, with other 3 classes in between. From the results we observed that there was an improvement in 6 categories of analysis after the regularization process, which were evidenced in $65 \%$ of the 34 variables evaluated by the comparison between the two periods. The final UEQI pointed out an index of 40.15 in the previous regularization period, which was framed in class D, therefore in an unsatisfactory quality level. In the second period, the rate was 72.98 , classifying the environmental quality of Vila Terra Santa in B, which is very satisfactory. The results of the indices in UEQ demonstrated the feasibility of applying them as a support tool for managers in decision-making.

Keywords: irregular occupation; urban environmental quality index; environmental management.

\section{Introdução}

Durante o século 20, as cidades brasileiras passaram por um crescimento e um adensamento populacional que esteve atrelado ao processo de desenvolvimento econômico do país e também por migrações da área rural para urbana, que resultaram em metrópoles fortemente marcadas por ocupações irregulares (Ermínia, 2003).

As ocupações irregulares estão, geralmente, situadas em áreas ambientalmente vulneráveis, como em Áreas de Preservação Permanente (APP), e são caracterizadas por aglomerações urbanas, sem nenhum ou pouco planejamento urbanístico. As moradias apresentam-se em condições precárias de habitabilidade, sem acesso a infraestrutura, equipamentos públicos e serviços essenciais (Rolnik, 2006).
Segundo Grostein (2001), as cidades informais, isto é, espaços com ocupação desordenada, crescem na ilegalidade urbana aumentando as diferenças socioambientais, contribuindo para a formação de espaços sem atributos de urbanidade e modificados bruscamente - em sua paisagem. No âmbito social, os danos são a perda de referência do ser humano com o lugar e o empobrecimento da cultura e da identidade (Borja, 1998).

Os dados do Censo 2010 (IBGE, 2010), revelaram que o Brasil possuía mais de 11,4 milhões de ocupações irregulares, representando $6 \%$ da população total do Brasil de 190 milhões de pessoas. $\mathrm{Na}$ Cidade de Curitiba, apesar de ter seu desenvolvimento acompanhado de planejamentos urbanos, não foi possível garantir um processo de urbanização isento de áreas sendo ocupadas de forma irregular. Uma das questões que não receberam o devido 
tratamento na instalação das áreas irregulares foi a condição da habitação para a população migrante e de baixa renda. Os primeiros registros de favelamento em área irregulares nesta cidade ocorreram na década de 50 (Hladczuk et al., 2000), em dados oficiais apontavam que em 2002 existiam no Município de Curitiba 13.136 domicílios localizados em APP(IPPUC, 2007), áreas consideradas impróprias para assentamentos.

A ocupação irregular em APP tornou-se a maior problemática no município de Curitiba em habitação de interesse social, pois esse tipo de assentamento caracteriza-se pela remoção da vegetação nativa, pela impermeabilização do solo e pela ocupação de áreas de alagamento natural do rio, que causam intensa degradação ambiental e riscos aos próprios moradores como possíveis enchentes e inundações (IPPUC, 2007).

Somente nos casos de utilidade pública, interesse social ou baixo impacto ambiental, previsto na Resolução CONAMA n ${ }^{\circ}$ 369/2006, pode-se haver uma intervenção ou supressão da vegetação, ou, quando autorizado pelo Órgão Ambiental competente e devidamente caracterizado (CONAMA, 2006; IPPUC, 2007).

O município de Curitiba vem promovendo a regularização fundiária das áreas de ocupações irregulares, desde a década de 70. A Companhia de Habitação Popular de Curitiba (COHAB-CT), é a responsável pela Política Habitacional do Município, em consonância com o Instituto de Pesquisa e Planejamento Urbano de Curitiba (IPPUC) e outras secretarias municipais. As melhorias habitacionais e urbanísticas de assentamentos degradados e em regularização fundiária objetivam proporcionar níveis melhores de qualidade de vida à população-alvo, diminuir os impactos ambientais negativos gerados e adequá-los à legislação urbana e ambiental (Abiko \& Coelho, 2009). Segundo Tanguay et al. (2010), os Indicadores de Desenvolvimento Sustentável (IDS), estão sendo cada vez mais utilizadas pelas administrações públicas, com o objetivo de apoiar suas estratégias de desenvolvimento sustentável, permitindo sistemas de avaliação e monitoramento.

Nesse contexto, o presente trabalho propõe aplicar uma metodologia para avaliação da Qualidade Ambiental Urbana (QAU), desenvolvida por Borja (1998) e adaptada pelas pesquisadoras, a fim de avaliar as informações aplicadas em um estudo de caso e verificar a possibilidade de gerar índices para este tipo de avaliação.

$\mathrm{O}$ estudo de caso foi a Vila Terra Santa, em Curitiba-PR, ocupação irregular localizada em APP, escolhida para a aplicação da metodologia de QAU para esta pesquisa. Dados levantados antes (período I: 2000-2007) e depois (período II: 2008-2013) do processo de regularização fundiária, possibilitaram aplicar, adaptar e comparar a QAU em dois períodos distintos e verificar a viabilidade de gerar um Índice de Qualidade Ambiental Urbana (IQAU) parcial e final, assim como categorizar em classes os valores dos índices gerados.

Na concepção do IGBE (2010), apenas os indicadores de saneamento são considerados como sendo os correspondentes aos ambientais. Estes indicadores são insuficientes para auxiliar na compreensão e direcionamento de ações e intervenções urbanas, principalmente em processos de regularizações fundiárias. Assim como Borja (1998), as autoras desta pesquisa se propuseram a contribuir para aprimorar uma metodologia que possa auxiliar no processo de planejamento urbano, aplicando e adaptando o QAU. Autores como Tanguay et al. (2010), realizaram um levantamento dos Indicado- 
res de Desenvolvimento Sustentável aplicados em cidades e Cavalcanti et al. (2017), avaliaram projetos voltados a mobilidade urbana que utilizaram Indicadores de Sustentabilidade, todos baseados no tripé social, econômico e ambiental.

As adaptações de variáveis e indicadores que pudessem alimentar a metodologia do QAU com informações quali-quantitativas dos aspectos socioambientais e de infraestrutura básica se mostraram necessárias. Estas adaptações auxiliariam na compreensão da relação dos aspectos do modo de vida com o uso inadequado e não planejado do solo, aliado ao meio físico natural. Além das adaptações, a possibilidade de agrupar todos os dados da metodologia e desenvolver um IQAU parcial e final, foram os motivadores para a realização desta pesquisa.

O IQAU parcial e final podem ser graduados indicando ainda diferentes níveis de qualidade que podem ser representados em classes específicas. Esta forma de apresentação dos dados em índices e classes, que, segundo Tanguay et al. (2010), permite aos gestores identificar de forma prática quais ações e projetos são os mais relevantes para se desenvolver em uma determinada área urbana, permitindo assim um planejamento mais adequado e sistêmico que esteja atento à qualidade urbana, incluindo os diferentes fatores socioambientais e econômicos.

O objetivo desta pesquisa foi analisar e adaptar a metodologia de Borja (1998) para QAU, aplicando-a em um estudo de caso para ser avaliado em dois períodos distintos, de modo a verificar, por meio da comparação entre esses períodos, a viabilidade de desenvolver IQAU parciais e finais suficientes para expressar a capacidade daquele espaço urbano em satisfazer as necessidades da população quanto à qualidade de vida e ambiental, ou seja, a qualidade ambiental urbana.

\section{Metodologia}

Esta pesquisa visou a aplicação da Metodologia da QAU, desenvolvida por Borja (1998), em um estudo de caso - Vila Terra Santa, localizada no município de Curitiba/PR, comparando dados levantados em dois períodos distintos. O período I, considerando a área do estudo de caso como sendo de ocupação irregular, com dados levantados pela COHAB-CT $(2005 ; 2008)$ para os anos de 2000 a 2007; e o período II quando ocorre a intervenção para a regularização da área, que abrange os anos de 2008 a 2013. O desenvolvimento desta pesquisa se deu em quatro etapas descritas a seguir.

Na primeira etapa da avaliação, foi realizada a caracterização da área por levantamento histórico da ocupação a partir de dados secundários que foram obtidos em base de dados oficiais disponibilizados na internet das seguintes instituições: Instituto Brasileiro de Geografia e Estatística (IBGE); Instituto Nacional de Pesquisas Espaciais (INPE); Ministérios das Cidades (Mcid); Ministério do Meio Ambiente (MMA); Governo do Estado do Paraná e suas respectivas Secretarias; Prefeitura Municipal de Curitiba (PMC); Institutos de Pesquisa e Planejamento Urbano de Curitiba (IPPUC); Companhia de Habitação Popular de Curitiba (COHAB-CT) e Companhia de Saneamento do Paraná (SANEPAR). Os dados secundários foram incluídos em um banco de dados Excel formatado pelas pesquisadoras.

A segunda etapa foi o levantamento de dados primários que foram obtidos por meio de entrevistas realizadas com informantes qualificados, tanto 
da gestão pública como assistentes sociais, engenheiros e arquitetos funcionários da COHAB-CT quanto da população residente na Vila Terra Santa e de lideranças comunitárias e moradores. Para a coleta dos dados primários na área de regularização fundiária Vila Terra Santa, foram realizadas duas visitas técnicas (nos dias 19/01/2013 e 21/02/2013), com o objetivo de fazer o reconhecimento da área para observar e confirmar os dados primários, obtidos por meio das entrevistas com os informantes qualificados, assim como avaliar in loco os dados secundários levantados. As observações, referentes à coleta de dados primários foram registrados em diário de bordo.

Na terceira etapa foi realizada a inserção dos dados secundários e primários coletados para os dois períodos, referentes às variáveis e indicadores para cada categoria de análise, em uma planilha Excel, para a aplicação da metodologia de QAU no estudo de caso de forma espaço-temporal para mensurar a QAU no período I e período II para posterior comparação. A metodologia com as adaptações concluídas, que pode ser visualizada na Tabela 1 , considerou oito categorias de análise compostas por um conjunto de variáveis que são mensuradas por um ou mais indicadores apresentados em porcentagem e cada indicador possui um peso correspondente pré-estabelecido pela metodologia. Os indicadores, quando ponderados e agregados com os seus respectivos pesos parciais, produzem o IQAU parcial por categoria e, a agregação das categorias com os pesos finais, formam o IQAU final.

Os indicadores ambientais urbanos, apresentados na Tabela 1, pretendem permitir uma avaliação objetiva, na qual são expressadas informações de forma quali ou quantitativa representada em percentuais com intervalos de $0-100$. Alguns indicadores tiveram que ser analisados de forma diferenciada, quando aplicados nesta pesquisa, como: cobertura da rede por torneira comunitária; domicílios atendidos por fossa séptica e coleta com caçamba.

Esses indicadores foram avaliados no período I, considerando que quanto maior o valor em porcentagem contabilizado melhor seria o indicador. No entanto, para o período II esse conceito foi invertido: partiu-se da análise de que em um processo de regularização fundiária, indicadores como esses, quanto menores fossem suas porcentagens melhor poderiam contribuir para a QAU. Portanto, nesses casos, a porcentagem foi contabilizada conforme a Equação 1 a seguir:

\section{EQUAÇÃO 1: Porcentagem final do} Indicador $=(100-$ valor atribuido $) \%$

As variáveis e indicadores que foram adaptados da metodologia de Borja (1998) para esta pesquisa, estão indicadas com asterisco na Tabela 2, na qual constam os pesos parciais e finais para cada indicador e variável, respectivamente. Os pesos parciais e finais atribuídos aos indicadores e às categorias de análise consideram o grau de importância voltada aos aspectos socioambientais definidas por Borja (1998), em suas pesquisas, e os adaptados foram definidos pelas autoras. Para a obtenção dos índices parciais, foram utilizados cálculos de médias ponderadas considerando a Equação 2:

EQUAÇÃO 2:

$I Q A U$ parcial/categoria $=\left[\frac{\left(v_{1} \mathrm{X}_{p} v_{1}\right)+\left(v_{2} \mathrm{X}_{p} v_{2}\right)+\cdots+\left(v_{n} \mathrm{X} p v_{n}\right)}{p v_{1}+p v_{2}+\cdots+p v_{n}}\right]$

Em que:

$I Q A U$ parcial é o índice resultante da agregação de todas as variáveis de uma determinada 


\section{categoria de análise e seus respectivos pesos pré- estabelecidos.

TABELA 1 - Categorias de Análise com suas variáveis e Indicadores de Qualidade Ambiental Urbana - QAU e respectivos percentuais.

\begin{tabular}{|c|c|c|c|}
\hline $\begin{array}{l}\text { CATEGORIA } \\
\text { DE ANÁLISE }\end{array}$ & VARIÁVEL & $\begin{array}{l}\text { INDICADORES DE } \\
\text { MELHOR QAU }\end{array}$ & PERCENTUAIS - de 0 a $100 \%$ \\
\hline \multirow[b]{2}{*}{ MORADIA } & $\begin{array}{l}\text { Situação do } \\
\text { domicílio }\end{array}$ & Imóvel ser próprio. & $100 \%$ \\
\hline & $\begin{array}{l}\text { Tipologia cons- } \\
\text { trutiva }\end{array}$ & $\begin{array}{l}\text { Moradias de alvenaria/ } \\
\text { tijolos. }\end{array}$ & $100 \%$ \\
\hline \multirow{6}{*}{ SANEAMENTO } & $\begin{array}{l}\text { Abastecimento } \\
\text { de água (con- } \\
\text { sumo) }\end{array}$ & $\begin{array}{l}\text { Consumo de água per } \\
\text { capita superior a } 1001 / \\
\text { hab./dia, para residên- } \\
\text { cias de padrão popular, } \\
\text { conforme o Manual de } \\
\text { Projetos Hidrossanitários } \\
\text { da SANEPAR. }\end{array}$ & Valores: na média $=50 \%$; acima da média $=100 \%$; abaixo da média $=0 \%$ \\
\hline & Cobertura & $\begin{array}{l}\text { Atendimento da totalida- } \\
\text { de de domicílios pela } \\
\text { rede da SANEPAR. }\end{array}$ & $100 \%$ \\
\hline & $\begin{array}{l}\text { Regularidade } \\
\text { do serviço }\end{array}$ & $24 \mathrm{~h}$ por dia. & $\begin{array}{l}\text { Para } 24 \mathrm{~h} \text { por dia }=100 \% \text {; com interrupções diárias }=75 \% \text {; para } 3 \text { a } 4 \text { vezes } \\
\text { por semana }=50 \% \text {; para } 3 \text { a } 4 \text { vezes por mês }=25 \%\end{array}$ \\
\hline & $\begin{array}{l}\text { Esgotamento } \\
\text { sanitário }\end{array}$ & $\begin{array}{l}\text { Atendimento da totalida- } \\
\text { de de domicílios com } \\
\text { rede de esgoto ou fossa } \\
\text { séptica. }\end{array}$ & $100 \%$ \\
\hline & $\begin{array}{l}\text { Drenagem } \\
\text { urbana }\end{array}$ & $\begin{array}{l}\text { Existência dos elementos } \\
\text { de drenagem urbana. }\end{array}$ & $100 \%$ para existência - 0\% para inexistência \\
\hline & $\begin{array}{l}\text { Frequência da } \\
\text { coleta }\end{array}$ & Diária ou alternada. & $\begin{array}{l}\text { Diária ou Alternado }=100 \% ; 1 \text { vez por semana }=75 \% ; 1 \text { vez por mês }= \\
50 \% ; \text { Esporádica }=25 \%\end{array}$ \\
\hline
\end{tabular}




\begin{tabular}{|c|c|c|c|}
\hline \multirow{4}{*}{$\begin{array}{l}\text { INFRAESTRU- } \\
\text { TURA } \\
\text { URBANA }\end{array}$} & $\begin{array}{l}\text { Pavimentação } \\
\text { das vias }\end{array}$ & $\begin{array}{l}\text { Atendimento da totalida- } \\
\text { de das vias do loteamento } \\
\text { com asfalto ou parale- } \\
\text { lepípedo. }\end{array}$ & $100 \%$ \\
\hline & $\begin{array}{l}\text { Pavimenta- } \\
\text { ção das vias } \\
\text { (estado) }\end{array}$ & Bom a ótimo. & $\begin{array}{l}\text { Ótimo } 9=100 \% \text {; Bom } 6,5=72,3 \% \text {; Regular } 4,5=50 \% ; \text { Péssimo } 2,5= \\
27,7 \%\end{array}$ \\
\hline & Calçadas & $\begin{array}{l}\text { Atendimento da } \\
\text { totalidade das vias do } \\
\text { loteamento com calçadas } \\
\text { de paralelepípedo, placa } \\
\text { de concreto, grama ou } \\
\text { asfalto. }\end{array}$ & $100 \%$ \\
\hline & $\begin{array}{l}\text { Calçadas } \\
\text { (estado) }\end{array}$ & Bom a ótimo. & $\begin{array}{l}\text { Ótimo } 9=100 \% \text {; Bom } 6,5=72,3 \% ; \text { Regular } 4,5=50 \% ; \text { Péssimo } 2,5= \\
27,7 \%\end{array}$ \\
\hline \multirow{4}{*}{$\begin{array}{l}\text { S E R V I Ç O S } \\
\text { URBANOS }\end{array}$} & $\begin{array}{l}\text { Abastecimento } \\
\text { comercial }\end{array}$ & Existência. & $\begin{array}{l}\text { Existência: Mercado; Farmácia; Panificadora; Lojas de Roupa; Material } \\
\text { de Construção; Papelaria; Gás. } 7 \text { itens }=100 \% .6 \text { itens }=85,7 \% .5 \text { itens } \\
=71,4 \% .4 \text { itens }=57,1 \% .3 \text { itens }=42,86 \% .2 \text { itens }=28,58 \% .1 \text { item }= \\
\text { 14,28\%. } 0 \text { item }=0 \% .\end{array}$ \\
\hline & $\begin{array}{l}\text { Abastecimento } \\
\text { de serviço }\end{array}$ & Existência. & $\begin{array}{l}\text { Existência de: Banco; Instituições Religiosas; Lotérica; Chaveiro. } 4 \text { itens }= \\
100 \% .3 \text { itens }=75 \% .2 \text { itens }=50 \% .1 \text { item }=25 \% .0 \text { item }=0 \% .\end{array}$ \\
\hline & Correio & $\begin{array}{l}\text { Atendimento da totalida- } \\
\text { de de domicílios como } \\
\text { por correio porta-porta e } \\
\text { existência de agências de } \\
\text { correio. }\end{array}$ & $100 \%$ \\
\hline & Transporte & $\begin{array}{l}\text { Linhas de ônibus atenden- } \\
\text { do dentro do loteamento e } \\
\text { Distância ótimo de ponto } \\
\text { de ônibus }<300 \mathrm{~m} \text {. }\end{array}$ & $\begin{array}{l}\text { Distâncias < 300m: Bom }=100 \% \text {; Distâncias 300-500m: Regular }=50 \% \text {; } \\
\text { Distâncias }>500: \text { Ruim }=0 \%\end{array}$ \\
\hline \multirow{4}{*}{$\begin{array}{l}\text { INFRAESTRU- } \\
\text { TURA } \\
\text { SOCIAL/ } \\
\text { CULTURAL }\end{array}$} & Saúde & Existência. & $\begin{array}{l}100 \% \text { - Existência com relação à capacidade e o número de habitantes - } \\
\text { Atendimento total do público alvo } 100 \% \text {; Atendimento parcial } 50 \% \text {; Sem } \\
\text { atendimento } 0 \%\end{array}$ \\
\hline & Educação & Existência. & $\begin{array}{l}\text { Existência: Ensino Infantil; Ensino Fundamental 1; Ensino Fundamental 2; } \\
\text { Ensino Médio. } 4 \text { itens }=100 \% .4 \text { itens com atendimento parcial } *=87,5 \% \text {. } \\
3 \text { itens }=75 \% .3 \text { itens com atendimento parcial } *=62,5 \% .2 \text { itens }=50 \% .2 \\
\text { itens com atendimento parcial } *=37,5 \% .1 \text { item }=25 \% .1 \text { item com atendi- } \\
\text { mento parcial } *=12,5 \% \text {. Para nenhum item }=0 \% \text {. }\end{array}$ \\
\hline & Lazer & Existência. & $100 \%$ para existência - $0 \%$ para inexistência \\
\hline & Cultura & Existência. & $100 \%$ para existência - $0 \%$ para inexistência \\
\hline
\end{tabular}




\begin{tabular}{|c|c|c|c|}
\hline $\begin{array}{c}\text { CONF O RTO } \\
\text { DO } \\
\text { AMBIENTE }\end{array}$ & $\begin{array}{l}\text { Água (corpo } \\
\text { hídrico) }\end{array}$ & $\begin{array}{l}\text { Não lançamento de } \\
\text { efluentes e resíduos em } \\
\text { corpos hídricos. }\end{array}$ & $0 \%$ para existência - $100 \%$ inexistência \\
\hline \multirow{3}{*}{$\begin{array}{c}\text { P A I S A G E M } \\
\text { URBANA }\end{array}$} & Arborização & $\begin{array}{l}\text { Atendimento da totalida- } \\
\text { de das vias do } \\
\text { loteamento com arbori- } \\
\text { zação. }\end{array}$ & Valores: na média $=50 \%$; acima da média $=100 \%$; abaixo da média $=0 \%$ \\
\hline & Sinalização & $\begin{array}{l}\text { Existências de vias com } \\
\text { sinalização. }\end{array}$ & $100 \%$ para existência - $0 \%$ para inexistência \\
\hline & Áreas verdes & $\begin{array}{l}\text { Índice de área verde } \\
\text { acima de } 8 \mathrm{~m}^{2} / \text { hab. } \\
\text { conforme determinação } \\
\text { do IBAMA. }\end{array}$ & $100 \%$ para existência - $0 \%$ para inexistência \\
\hline \multirow{3}{*}{ CIDADANIA } & $\begin{array}{l}\text { Segurança } \\
\text { pública }\end{array}$ & Taxa de homicídios. & Valores: na média $=50 \%$; abaixo da média $=100 \%$; acima da média $=0 \%$ \\
\hline & Informação & $\begin{array}{l}\text { Existência de bancas de } \\
\text { revistas. }\end{array}$ & $100 \%$ para existência - $0 \%$ para inexistência \\
\hline & $\begin{array}{l}\text { Organização } \\
\text { popular }\end{array}$ & $\begin{array}{l}\text { Existência de grupos } \\
\text { organizados. }\end{array}$ & $100 \%$ para existência - $0 \%$ para inexistência \\
\hline
\end{tabular}

Fonte: Autoria própria baseado em Borja (1998).

${ }^{1}$ Companhia de Saneamento do Paraná (SANEPAR); ${ }^{2}$ Secretaria Municipal do Meio Ambiente (SMMA); ${ }^{3}$ Companhia Paranaense de Energia (COPEL);

${ }^{4}$ Instituto Brasileiro do Meio Ambiente e dos Recursos Naturais Renováveis (IBAMA);*Atendimento parcial - não possui vagas suficientes para atender a comunidade da Vila Terra Santa.

TABELA 2 - Categorias de análise, variáveis propostas e indicadores da Qualidade Ambiental Urbana - QAU.

\begin{tabular}{|c|c|c|}
\hline $\begin{array}{c}\text { CATEGORIA DE } \\
\text { ANÁLISE }\end{array}$ & VARIÁVEL & INDICADORES DE QAU \\
\hline \multirow{3}{*}{ MORADIA } & \multirow{2}{*}{ Situação do domicílio } & \% de ocupantes de imóvel próprio* \\
\hline & & $\%$ de ocupantes de imóvel alugado*;2 \\
\hline & Tipologia construtiva & $\%$ de moradias com tijolo e/ou alvenaria \\
\hline & \multirow{2}{*}{ Cobertura } & \% de domicílios com rede e hidrômetro individual \\
\hline & & $\%$ de domicílios com rede e torneira comunitária ${ }^{* ; 2}$ \\
\hline & Regularidade do serviço & $\%$ de domicílios com rede 24 horas por dia \\
\hline & Esgotamento sanitário & $\%$ de domicílios com fossa séptica ${ }^{1}$ \\
\hline \multirow[t]{2}{*}{ SANEAMENTO } & \multirow[t]{2}{*}{ Drenagem urbana } & $\%$ de vias com canal \\
\hline & & $\%$ de vias com galeria \\
\hline
\end{tabular}




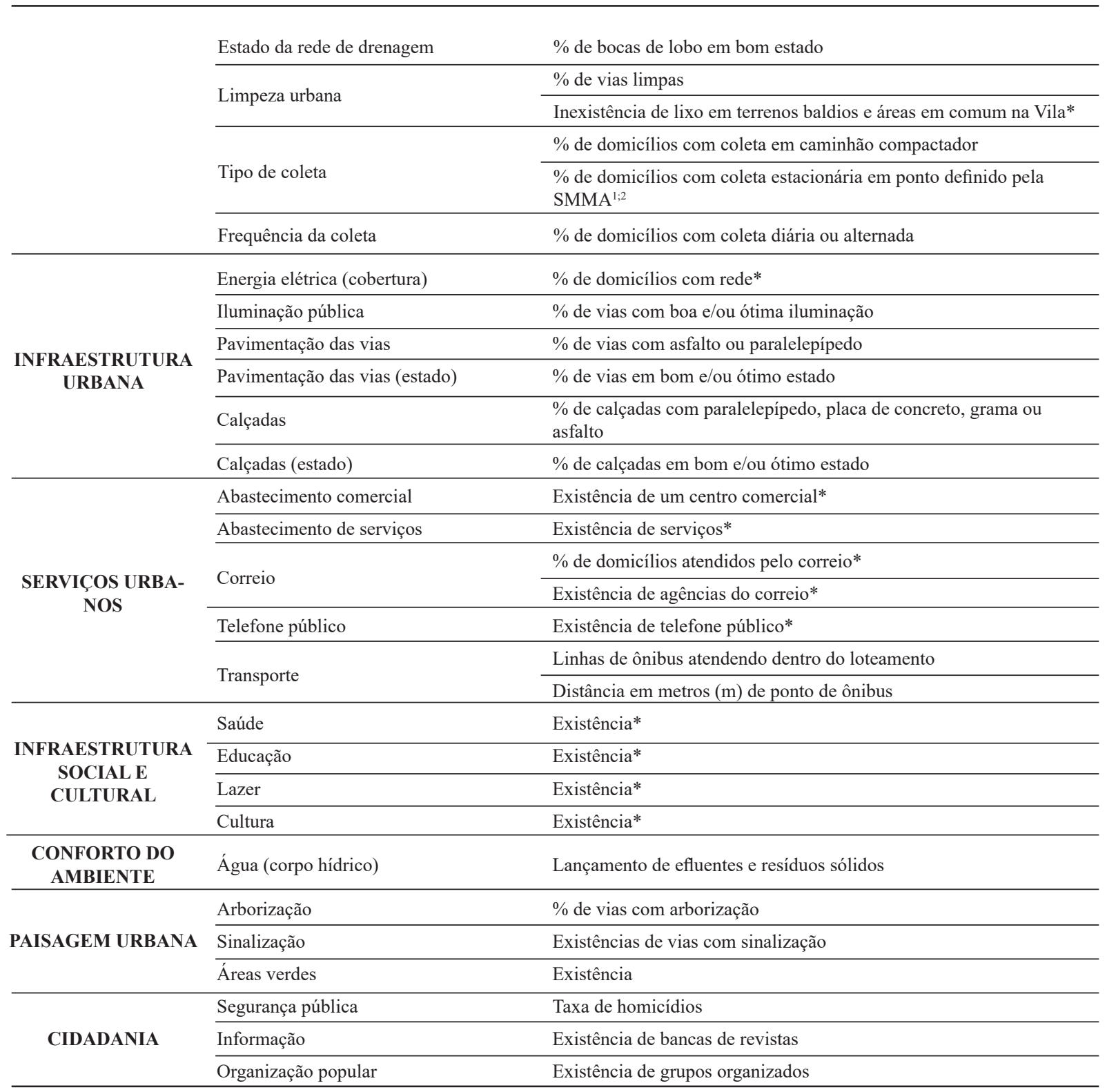

Fonte: Autoria própria baseado em Borja (1998).

*Indicadores adaptados.

${ }^{1}$ Secretaria Municipal do Meio Ambiente - SMMA

${ }^{2}$ Indicadores contabilizados no período I com valores de 0 a $100 \%$, quanto maior o valor do indicador melhor. No período II, foram contabilizados valores invertidos, quanto menor o valor do indicador presente, melhor, ou seja, se apresentar valor contabilizado em 5\% será correspondente a $95 \%$ (100 - valor atribuído $=\%$ final do indicador $)$. 
A Etapa 4 consistiu em obter o IQAU final após a aplicação do sistema de indicadores, utilizando a Equação 3:

\section{EQUAÇÃO 3:}

$I Q A U$ final $=\left[\frac{\left(c_{1} \mathrm{X} p c_{1}\right)+\left(c_{2} \mathrm{X} p c_{2}\right)+\cdots+\left(c_{n} \mathrm{X} p c_{n}\right)}{p c_{1}+p c_{2}+\cdots+p c_{n}}\right]$

Em que:

$I Q A U$ final é o índice resultante da agregação de todas as categorias de análise e seus respectivos pesos.

$c_{n}$ é a categoria de análise avaliada.

$p c_{n}$ é o peso da categoria correspondente.

A aplicação do sistema QAU foi realizada em dois momentos distintos, o período I e o período II. O ano de 2013 não corresponde necessariamente ao fim da regularização fundiária do estudo de caso, mas sim ao fim da coleta de dados para esta pesquisa, ou seja, é um recorte espaço-temporal. A análise final desta pesquisa se dá comparando os IQAU finais de cada período, a fim de identificar as alterações socioambientais e de infraestrutura apresentadas na Vila Terra Santa, e verificar a viabilidade de aplicá-los.
Para estabelecer uma graduação indicando níveis nos Índices de Qualidade Ambiental UrbanaIQAU, definiu-se por utilizar 5 classes de qualidade que vão da extremamente satisfatória para muito insatisfatória, conforme adaptações das autoras e seguindo as orientações de Borja (1998), associadas ao valor do índice de QAU, e que poderiam ser inseridas em classes de Qualidade, conforme indicado no Tabela 3.

Esta possibilidade de apresentar o IQAU final em níveis e enquadrar o resultado em classes pode auxiliar os gestores a enxergar de forma prática e relevante a situação, podendo assim subsidiar a tomada de decisão para as ações e projetos a serem desenvolvidos. Essa metodologia do QAU pode auxiliar na análise mais sistêmico sobre o planejamento urbano voltado à qualidade urbana utilizando fatores socioambientais.

TABELA 3 - Classes de Qualidade Ambiental Urbana.

\begin{tabular}{ccc}
\hline Classe de Qualidade & Nível de QAU & Valor do Índice de QAU \\
\hline A & Extremamente satisfatório & $81-100$ \\
B & Muito satisfatório & $61-80$ \\
C & Satisfatório & $41-60$ \\
D & Insatisfatório & $21-40$ \\
E & Muito insatisfatório & $0-20$ \\
\hline
\end{tabular}

FONTE: Autoria própria baseado em Borja (1998). 


\section{Resultados e discussão}

\subsection{Histórico da ocupação - Vila Terra} Santa

A Vila Terra Santa surgiu em 1998, resultante de uma ocupação irregular que abrangeu uma área de aproximadamente $240.000 \mathrm{~m}^{2}$, de uma propriedade particular localizada no Bairro Tatuquara/ Curitiba. A partir do ano de 2000, as informações sobre esta área começaram a ser levantas pela COHAB-CT (2005), para compor dados que pudessem auxiliar no processo de regularização fundiária.
A ocupação da área da Vila Terra Santa foi desencadeada por moradores mais antigos e lideranças comunitárias. Ao final de 1998 e início de 1999 a ocupação invadiu a área com concentração de vegetação nativa (Figura 1A), e ocorreu grave devastação ambiental seguida de ocupações individuais (Figura 1B) ao longo das faixas de APP (COHAB-CT, 2005). Este adensamento populacional, inevitavelmente necessitava de espaço e, no início de 1999, a ocupação se expandiu na área com concentração de vegetação nativa.

Até o início do processo de regularização fundiária, este local era cadastrado pela Secretaria Municipal de Meio Ambiente (SMMA) como Bosque Nativo Relevante, por ser uma área de mata na-
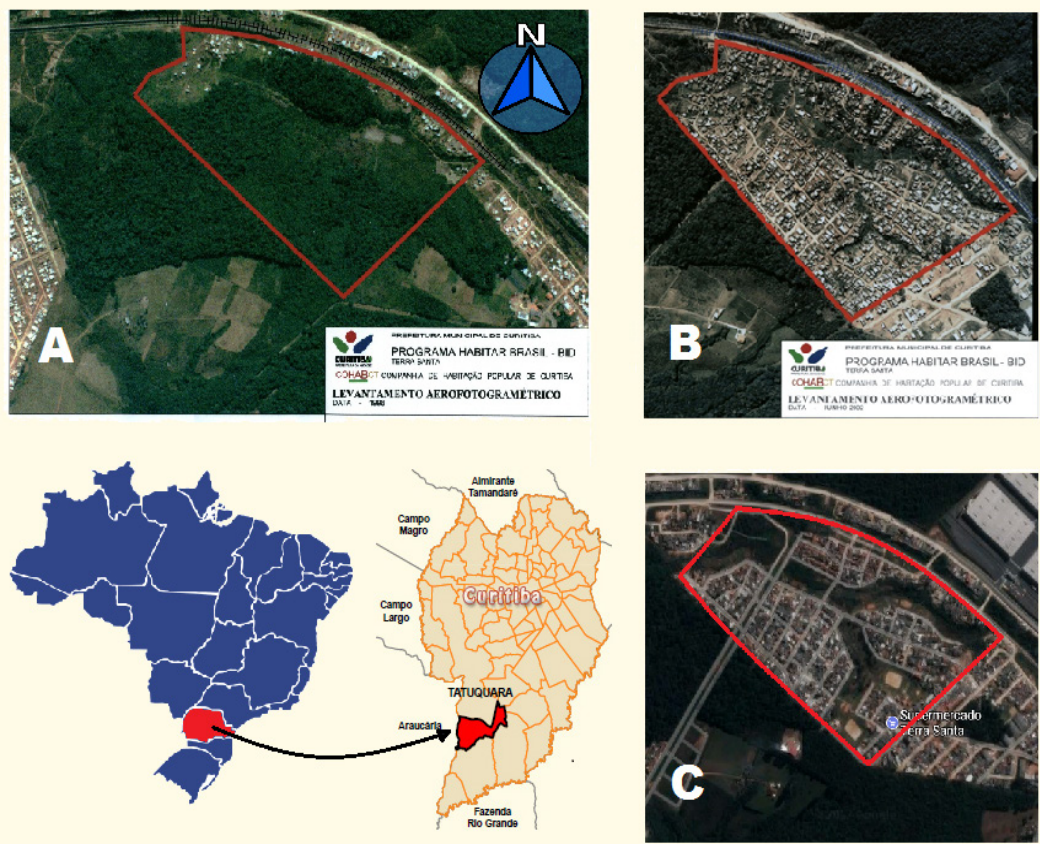

FIGURA 1 - Localização da Vila terra Santa localizada no bairro Tatuquara em Curitiba/PR.

Legenda: A - área anterior à invasão que daria origem a Vila Terra Santa; B - área invadida correspondente ao período de avaliação desta pesquisa de 2000-2007; C - área regularizada pela COHAB-CT correspondente ao período de avaliação de 2008 a 2013. Coordenadas geográficas 1A; 1B e 1C: $-25.558516,-49.318821$ Escala das fotografias aéreas: $1 \mathrm{~cm}=600 \mathrm{~m}$.

FONTE: COHAB-CT (2002) para figuras A e B; Google Maps (2017) - figura C. 
tiva cortada por inúmeros córregos e duas nascentes. Durante o processo de ocupação, $70 \%$ de vegetação foi suprimida (Figura 1A), e entre o período de 1998 até 2007, a ocupação se estendeu ao longo das áreas de APP dos córregos e nascentes (COHAB-CT, $2005 ; 2008)$.

A ocupação da vila se deu por famílias que estavam em situação de vulnerabilidade, vivendo em condições de subemprego, renda insuficiente, baixa escolaridade, sem possibilidades de adquirir um imóvel por vias formais. A situação que já era precária foi agravada pela falta de condições de saneamento básico e carência de equipamentos públicos para atendimento à população (COHAB-CT, 2008).

Em relação às características socioeconômicas, no início do diagnóstico de intervenção, em 2004, a população desta área estava estimada em 3.164 moradores de população jovem com destaque para a faixa entre 18 e 30 anos, na qual $64,8 \%$ das pessoas tinham até 30 anos de idade, e 77,5\% das mulheres eram chefes de família - sugerindo que as mulheres tinham a responsabilidade pela moradia, com ou sem cônjuge - e a renda mensal era de um salário mínimo (COHAB-CT, 2005; 2008).

Na Vila Terra Santa verificou-se a existência de 1.077 famílias vivendo em habitações insalubres e/ou situações de risco (Figura 1B). Desse total, a COHAB-CT previu, no projeto de intervenção, duas etapas distintas: a relocação de famílias e a urbanização da Vila. Foram relocadas 479 famílias para o novo loteamento da COHAB-CT denominado Moradias Laguna. Na Vila Terra Santa permaneceram 598 famílias, foram implantadas 171 novas moradias e realizadas 223 melhorias habitacionais, além da implantação da infraestrutura básica e rede de coleta de esgoto (COHAB-CT, 2008).
Para adequar a Vila Terra Santa à Legislação Ambiental e urbanística foram promovidas intervenções para resgatar condições mínimas necessárias ao cumprimento dos acordos firmados com o Ministério Público do Meio Ambiente. Estes acordos previam a desocupação das faixas de preservação permanente de 30 metros para cada lado dos córregos existentes e de um círculo de 50 metros de raio a partir de suas nascentes (Figura 1C). A seguir serão apresentados os resultados voltados à aplicação da metodologia do QAU, a fim de avaliar a viabilidade de desenvolvimento de índices.

\subsection{Resultados para as categorias de análise, variáveis e indicadores da $Q A U$}

A comparação entre o período com informações da ocupação irregular, do ano 2000 a 2007 período I - e após o início da intervenção da COHAB-CT, para regularização da área, considerando o período entre 2008 a 2013 - período II, foi realizada para cada uma das 8 (oito) categorias de análise do QAU, que são: Moradia, Saneamento, Infraestrutura Urbana, Serviços Urbanos, Infraestrutura Social e Cultural, Conforto do Meio Ambiente, Paisagem Urbana e Cidadania. Para cada categoria de análise foi atribuído um Índice da Qualidade Urbana - o IQUA parcial.

\subsubsection{Moradia}

Os resultados obtidos para a categoria de análise Moradia, assim como as médias ponderadas obtidas por meio do levantamento dos indicadores que compõem as variáveis desta categoria podem 
ser visualizados na Tabela 4, para cada um dos dois períodos analisados. rizada por baixo padrão de acabamento, resultado de um processo de ocupação improvisado. Nesse

TABELA 4 - Resultados dos indicadores, classe e IQAU parcial na categoria Moradia para os dois períodos analisados.

\begin{tabular}{lcccccccc}
\hline & & \multicolumn{2}{c}{ Período I (2000 a 2007) } & \multicolumn{2}{c}{ Período II (2008 a 2013) } \\
\cline { 3 - 8 } CATEGORIA & VARIÁVEL & $\begin{array}{c}\text { Médias } \\
\text { Ponderadas } \\
\text { indicadores }\end{array}$ & $\begin{array}{c}\text { Classe de } \\
\text { Qualidade }\end{array}$ & $\begin{array}{c}\text { IQAU } \\
\text { Par- } \\
\text { cial }\end{array}$ & $\begin{array}{c}\text { Médias Ponde- } \\
\text { radas } \\
\text { indicadores }\end{array}$ & $\begin{array}{c}\text { Classe de } \\
\text { Qualidade }\end{array}$ & $\begin{array}{c}\text { IQAU } \\
\text { Parcial }\end{array}$ \\
\hline \multirow{2}{*}{ MORADIA } & Situação do domicílio & 45,15 & $\mathrm{C}$ & & 100 & $\mathrm{~A}$ & \\
& Tipologia construtiva & 16,8 & $\mathrm{E}$ & 49,8 & 38,65 & $\mathrm{D}$ & 77,69 \\
& Conforto & 100 & $\mathrm{~A}$ & & 100 & $\mathrm{~A}$ & \\
\hline
\end{tabular}

FONTE: Autoria própria.

Nesta categoria a variável situação do domicílio, no período I, o nível de qualidade era classe C contando com $89,7 \%$ da população com imóvel próprio e $0,6 \%$ alugado. Iniciado o processo de regularização fundiária, período II avaliado, ocorreu o reassentamento de 479 famílias (em 2009), para o conjunto habitacional Moradias Laguna, empreendimento localizado a $1 \mathrm{~km}$ da área da Vila Terra Santa.

O reassentamento modificou consideravelmente a quantidade de moradores, pois apenas um pouco mais da metade dos domicílios permaneceram no assentamento, aproximadamente 598 famílias, com isso a variável situação do domicílio passou para a classe de qualidade $\mathrm{A}$, no período II. Os moradores que permaneceram na Vila Terra Santa conquistaram documentação de posse do terreno, com 100\% das residências podendo ser consideradas como próprias.

Em relação à tipologia construtiva, o padrão das moradias no período I era típico de comunidades pobres de Curitiba e Região Metropolitana, caracte- período, a variável estava representada na classe $\mathrm{E}$ (muito insatisfatório).

No período II de regularização de 2008 a 2013, dentre as 598 famílias que permaneceram no assentamento, 171 moradias foram construídas pela COHAB-CT em alvenaria. Diversas melhorias habitacionais (instalação de módulos sanitários, reformas de telhados, entre outros) foram realizadas por meio de intervenções em 223 moradias já existentes. Ficou evidente uma melhoria na tipologia construtiva ao passar da classe E para a classe D (insatisfatório), conforme já foi apresentado na Tabela 4.

O IPPUC (2009), entende que ao analisar a densidade populacional em um domicílio remete-se a avaliar o conforto desse ambiente. Para a variável conforto quanto menor a densidade, melhor a distribuição de ocupantes pelos cômodos da casa, garantindo um convívio adequado às diferentes faixas etárias. Para esta variável, no período I, a densidade populacional da Vila Terra Santa era de 3,08 habitantes por domicílio (hab./dom.), ficando 
inferior à média da Capital para o mesmo ano do dado coletado (3,55hab./dom.).

No período II, a densidade habitacional da Vila passou para 2,5hab./dom. em 2010, sendo portanto menor quando comparada à densidade atribuída para Capital (3,25 hab./dom.) nesse mesmo ano. Isso mostra que, mesmo sendo densamente povoada, a distribuição dos habitantes não era considerado insatisfatória, o que manteve a variável conforto na classe A nos dois períodos.

A categoria Moradia, no período I, obteve um IQAU parcial de 49,8 sendo avaliada como classe C (satisfatório), e no período posterior 2 essa categoria melhorou passando para a classe B (muito satisfatório), apresentando um IQAU parcial de 77,69.

\subsubsection{Saneamento}

Para esta categoria foram consideradas nove variáveis, e o resultado em relação a classe de qua- lidade e IQAU parcial pode ser visualizado na Tabela 5.

Tendo em vista que a média de consumo para residências de padrão popular, abastecidas pela SANEPAR (Paraná, 2010), considera 100 L/hab./ dia como consumo ideal, a análise realizada para a variável abastecimento de água (consumo) demonstrava que o consumo para o ano de 2007 era de $92 \mathrm{~L} /$ hab./dia per capita, o que foi considerado baixo e por este motivo o período I ficou indicado na classe $\mathrm{E}$.

O consumo per capita de água avaliada no período II demonstrou um pequeno aumento, o que contribuiu para que o indicador passasse para a classe A, com o consumo médio de 103,66 L/hab./ dia, valor considerado adequado pela SANEPAR.

Para a variável cobertura, identificou-se que o abastecimento de água no período I atendia $94,35 \%$ dos domicílios, por meio da rede pública da SANE-

TABELA 5 - Resultados dos indicadores, classe e IQAU parcial na categoria Saneamento para os dois períodos analisados.

\begin{tabular}{|c|c|c|c|c|c|c|c|}
\hline \multirow[b]{2}{*}{ CATEGORIA } & \multirow[b]{2}{*}{ VARIÁVEL } & \multicolumn{3}{|c|}{ Período I (2000 a 2007) } & \multicolumn{3}{|c|}{ Período II (2008 a 2013) } \\
\hline & & $\begin{array}{c}\text { Médias Pon- } \\
\text { deradas } \\
\text { indicadores }\end{array}$ & $\begin{array}{l}\text { Classe de } \\
\text { Qualidade }\end{array}$ & $\begin{array}{c}\text { I Q A U } \\
\text { Parcial }\end{array}$ & $\begin{array}{c}\text { Médias Pon- } \\
\text { deradas } \\
\text { indicadores }\end{array}$ & $\begin{array}{l}\text { Classe de } \\
\text { Qualidade }\end{array}$ & $\begin{array}{l}\text { I Q A U } \\
\text { Parcial }\end{array}$ \\
\hline \multirow{9}{*}{ SANEAMENTO } & $\begin{array}{l}\text { Abastecimento de água } \\
\text { (consumo) }\end{array}$ & 0 & E & \multirow{9}{*}{49,8} & 100 & A & \multirow{9}{*}{81,37} \\
\hline & Cobertura & 47,17 & $\mathrm{C}$ & & 100 & A & \\
\hline & $\begin{array}{l}\text { Regularidade do } \\
\text { serviço }\end{array}$ & 100 & A & & 100 & A & \\
\hline & Esgotamento sanitário & 10,75 & E & & 100 & A & \\
\hline & Drenagem urbana & 0 & E & & 100 & A & \\
\hline & Estado da rede & 0 & E & & 50 & $\mathrm{C}$ & \\
\hline & Limpeza urbana & 0 & $\mathrm{E}$ & & 0 & E & \\
\hline & Tipo de coleta & 45,4 & $\mathrm{C}$ & & 100 & A & \\
\hline & Frequência da coleta & 100 & A & & 100 & A & \\
\hline
\end{tabular}

FONTE: Autoria própria. 
PAR. Desses domicílios, 84,7\% possuíam hidrômetro individual e $9,65 \%$ eram atendidos por uma torneira comunitária. Como nessa variável, tanto o indicador hidrômetro individual, quanto a torneira comunitária contabilizavam o que de melhor contribuía para a variável, ficou inserida na classe C. As ligações clandestinas representavam 3,22\% do total de fornecimento de água, o que na época demandou a previsão de extensão da rede. No período II verificou-se que todos os domicílios estavam interligados na rede de abastecimento de água e com hidrômetros individuais, portanto, a variável cobertura passou para a classe A.

A variável regularidade do serviço indicou que o fornecimento era regular e operado 24 horas por dia para os dois períodos avaliados, portanto, para ambos a variável obteve classe $\mathrm{A}$.

Em relação ao esgotamento sanitário, no período I, do total de domicílios 78,5\% lançavam o esgoto diretamente no solo por meio de fossas rudimentares ou a céu aberto, 13,7\% dos domicílios utilizava fossa séptica, e 7,8\% rede de coleta, sendo esta variável enquadrada na classe E. No período II, a rede coletora de esgoto foi implantada para 100\% dos domicílios, as fossas sépticas e rudimentares foram desativadas, e os efluentes tratados na Estação de Tratamento de Esgoto CIC Xisto (COHAB-CT, 2008), garantido a essa variável a classe A.

Em relação a variável drenagem urbana, no período I a Vila não era atendida por sistema de drenagem urbana, o que aumentava o risco de alagamentos e deslizamento de terra, o que a enquadrou na classe E. Em épocas de chuva, as águas pluviais, juntamente com os esgotos, transbordavam dos canais dos córregos existentes, alagando as casas próximas aos córregos. Essa situação estava se agravando com o assoreamento desses córregos, devido ao lançamento de resíduos sólidos.

No período II, a rede de drenagem urbana foi implantada no loteamento. Contudo, por meio das visitas técnicas, foi possível observar o estado da rede de drenagem implantada, observou-se a má conservação das sarjetas e bocas de lobo, com acúmulo de resíduos sólidos nestes locais, enquadrando-a na classe $\mathrm{C}$.

Para as variáveis tipo, frequência de coleta e limpeza urbana, foi identificado que no período I a coleta de resíduos sólidos, que acontecia por meio de uma caçamba estacionária contemplava 75,8\% dos domicílios, e a coleta porta a porta, realizada por caminhão compactador, atendia apenas $15 \%$ dos domicílios, sendo avaliada como classe C. Esse fato ocorria devido à dificuldade de acesso do caminhão compactador na Vila, em função de ruas estreitas, ou em precárias condições de conservação. A coleta convencional porta a porta era realizada somente em duas ruas e o restante dos domicílios era atendido através de seis caçambas estacionadas, localizadas em pontos estratégicos.

No período II, a coleta porta a porta era realizada regularmente a cada três dias, enquanto que a entrega voluntária em local definido foi desativada. Portanto, a frequência de coleta era alternada e atendeu adequadamente a demanda da Vila e a variável frequência de coleta foi considerada classe A.

Para a variável limpeza urbana, o período I foi considerado classe E porque as vias não eram atendidas por serviços de varrição e era comum a disposição e o acúmulo de resíduos em locais inadequados, como terrenos baldios e córregos. No período II, devido ao redimensionamento do sistema viário, a coleta de resíduos e varrição foi estendida a todos os domicílios, passando a ser classe A. A categoria de análise Saneamento obteve IQAU 
parcial de 49,8, classificado como C, no período I. Após as intervenções o IQAU parcial passou para a classe A com um valor de índice de 81,37.

\subsubsection{Infraestrutura urbana}

Para a categoria Infraestrutura urbana foram elencadas 6 variáveis, avaliadas pelos seus respectivos indicadores, como já demonstrado na Tabela 1, que compuseram por meio das médias ponderadas o IQAU parcial e sua respectiva indicação nas classes de qualidade, conforme pode ser visualizado na Tabela 6 para os dois períodos analisados.

A variável que indica o serviço de fornecimento de energia elétrica (cobertura), conforme Tabela 6, demonstra que no período I a Vila contava com $58,09 \%$ dos domicílios com medidor próprio, mas o restante dos domicílios era atendido por ligações clandestinas obtidas de terceiros ou diretamente dos postes, para tanto a variável foi indicada como classe C. No período II, o fornecimento de energia elétrica continuou inadequado para $48,31 \%$ dos domicílios que permaneceram no assentamento, a variável energia elétrica (cobertura) permaneceu na classe $\mathrm{C}$.

Quanto à variável iluminação pública, segundo dados da COHAB-CT (2005), para o período I este serviço indicava a classe D. No período II, por meio das visitas técnicas realizadas em 2013 e consulta aos projetos de iluminação foi possível observar a alocação dos postes e iluminação pública $100 \%$ concluída, indicando a classe A.

$\mathrm{Na}$ categoria de Infraestrutura Urbana, as variáveis pavimentação das vias e calçadas foram quantificadas em metro linear, em relação ao total da extensão linear das vias do loteamento. A espontaneidade do processo de ocupação irregular nos trechos da área que apresentavam acentuados declives do terreno resultou em uma organização caótica das vias de acesso, o que colaborou na pre-

TABELA 6 - Resultados dos indicadores, classe e IQAU parcial na categoria Infraestrutura Urbana para os dois períodos analisados

\begin{tabular}{|c|c|c|c|c|c|c|c|}
\hline \multirow[b]{2}{*}{ CATEGORIA } & \multirow[b]{2}{*}{ VARIÁVEL } & \multicolumn{3}{|c|}{ Período I (2000 a 2007) } & \multicolumn{3}{|c|}{ Período II (2008 a 2013) } \\
\hline & & $\begin{array}{l}\text { Médias Pon- } \\
\text { deradas } \\
\text { indicadores }\end{array}$ & $\begin{array}{l}\text { Classe de } \\
\text { Qualidade }\end{array}$ & $\begin{array}{l}\text { I Q A U } \\
\text { Parcial }\end{array}$ & $\begin{array}{l}\text { Médias Pon- } \\
\text { deradas } \\
\text { indicadores }\end{array}$ & $\begin{array}{l}\text { Classe de } \\
\text { Qualidade }\end{array}$ & $\begin{array}{l}\text { I Q A U } \\
\text { Parcial }\end{array}$ \\
\hline \multirow{6}{*}{$\begin{array}{l}\text { INFRAESTRUTURA } \\
\text { URBANA }\end{array}$} & $\begin{array}{l}\text { Energia elétrica } \\
\text { (cobertura) }\end{array}$ & 58,09 & $\mathrm{C}$ & \multirow{6}{*}{15,2} & 48 & $\mathrm{C}$ & \multirow{6}{*}{65,38} \\
\hline & Iluminação pública & 27,7 & $\mathrm{D}$ & & 100 & A & \\
\hline & $\begin{array}{l}\text { Pavimentação das } \\
\text { vias }\end{array}$ & 0 & $\mathrm{E}$ & & 98 & A & \\
\hline & $\begin{array}{l}\text { Pavimentação das } \\
\text { vias (estado) }\end{array}$ & 0 & $\mathrm{E}$ & & 72 & B & \\
\hline & Calçadas & 0 & $\mathrm{E}$ & & 26 & $\mathrm{D}$ & \\
\hline & Calçadas (estado) & 0 & E & & 50,00 & $\mathrm{C}$ & \\
\hline
\end{tabular}

FONTE: Autoria própria. 
cariedade do sistema viário naquela região. O subdimensionamento e a existência de ruas extremamente íngremes, praticamente inviabilizavam a circulação de veículos automotores.

As ruas não possuíam qualquer estrutura de base, ou seja, nenhuma pavimentação, e a falta de hierarquização de vias e subvias de ligação com os conjuntos do entorno tornaram os acessos inviáveis para o transporte público. A ausência de revestimentos de qualquer tipo era a principal característica do sistema viário no período I, e o seu enquadramento tanto da pavimentação, quanto da calçada foi na classe $\mathrm{E}$.

No período II a Vila Terra Santa recebeu intervenções drásticas no redimensionamento da largura de algumas vias e na abertura de outras. A realocação de postes de energia elétrica também foi necessária para permitir as ligações básicas previstas no projeto de diretrizes viárias da cidade. A Vila somente recebeu pavimentação em Concreto Betuminoso Usinado a Quente (CBUQ), e implementação de meio-fio após a conclusão das obras das redes de água, esgotamento sanitário e de drenagem das águas pluviais. A execução da pavimentação foi contemplada em $98 \%$ do total de vias, mas em duas travessas do loteamento houve resistência de moradores para fazer a pavimentação. A qualidade da pavimentação ficou como classe A depois das intervenções, no entanto o estado da pavimentação se enquadrou na classe B pelo fato de não ter sido complementada em 100\% das vias.

No período II, a implantação da calçada na testada dos lotes ficou sob responsabilidade de cada morador e a execução de ciclovias nas áreas de lazer sob responsabilidade da COHAB-CT. Até o ano de 2013, apenas as ciclovias estavam concluídas, a variável calçadas ficou como classe $\mathrm{D}$, e calçadas (estado) na classe E.

A categoria de análise Infraestrutura Urbana no período I, obteve um IQAU parcial de 15,2, no entanto, após o processo de intervenção, passou para um IQAU parcial de 65,38, o que corresponde a um nível de qualidade muito satisfatório.

\subsubsection{Serviços urbanos}

$\mathrm{Na}$ categoria de análise Serviços Urbanos (Tabela 7) foram consideradas as variáveis: abastecimento comercial (bancos, instituições religiosas, lotérica e chaveiro), abastecimento de serviço (mercado, farmácia, panificadora, lojas de roupa, material de construção, papelaria e distribuidora de gás), correio, telefone público e transporte. A inexistência para cada item definido reduz a qualidade da categoria de análise.

Para a variável correio, a Vila Terra Santa, no período I, não era atendida por serviços de correio porta a porta, a população precisava buscar suas correspondências em um mercado existente nas proximidades, e o seu enquadramento ficou na classe C.

No período II as correspondências puderam ser entregues porta a porta, visto que a ação de regularização da área permitiu a Secretaria Municipal de Urbanismo (SMU), cadastrar nomes de ruas e CEP, o que enquadrou esta variável na classe A.

Quanto a variável telefone público, no período I verificou-se a não existência de aparelhos de telefone público disponíveis, sendo atribuído a classe E, a população precisava sair da Vila para utilizar o telefone público. No período II foi instalado um telefone público na Vila, o que fez corresponder esta categoria à classe $\mathrm{A}$. 
TABELA 7 - Resultados dos indicadores, classe e IQAU parcial na categoria Serviços Urbanos para os dois períodos analisados.

\begin{tabular}{|c|c|c|c|c|c|c|c|}
\hline \multirow[b]{2}{*}{ CATEGORIA } & \multirow[b]{2}{*}{ VARIÁVEL } & \multicolumn{3}{|c|}{ Período I (2000 a 2007) } & \multicolumn{3}{|c|}{ Período II (2008 a 2013) } \\
\hline & & $\begin{array}{c}\text { Médias Pon- } \\
\text { deradas } \\
\text { indicadores }\end{array}$ & $\begin{array}{l}\text { Classe de } \\
\text { Qualidade }\end{array}$ & $\begin{array}{l}\text { I Q A U } \\
\text { Parcial }\end{array}$ & $\begin{array}{c}\text { Médias Pon- } \\
\text { deradas } \\
\text { indicadores }\end{array}$ & $\begin{array}{l}\text { Classe de } \\
\text { Qualidade }\end{array}$ & $\begin{array}{l}\text { I } \underset{\text { Parcial }}{\mathbf{A}} \text { A U } \\
\text { Paris }\end{array}$ \\
\hline \multirow{5}{*}{$\begin{array}{l}\text { SERVIÇOS } \\
\text { URBANOS }\end{array}$} & $\begin{array}{l}\text { Abastecimento } \\
\text { comercial }\end{array}$ & 100 & A & \multirow{5}{*}{55} & 100 & A & \multirow{5}{*}{100} \\
\hline & $\begin{array}{c}\text { Abastecimento de } \\
\text { serviço }\end{array}$ & 100 & A & & 100 & A & \\
\hline & Correio & 50 & $\mathrm{C}$ & & 100 & A & \\
\hline & Telefone público & 0 & E & & 100 & A & \\
\hline & Transporte & 25 & $\mathrm{D}$ & & 100 & A & \\
\hline
\end{tabular}

FONTE: Autoria própria.

A variável transporte público foi avaliada com relação às distâncias em metro linear em relação aos pontos de ônibus. Neste caso, foi considerada como situação ideal a indicação de Pianucci (2011), na qual a distância inferior a 300m é $100 \%$, regular entre 300 e $600 \mathrm{~m}(50 \%)$ e situação inadequada quando superior a $600 \mathrm{~m}(0 \%)$.

Em relação a variável transporte público, no período I foram identificadas seis linhas de ônibus, porém nenhuma entrava na Vila, devido à má condição do sistema viário. Os pontos destes ônibus geralmente distanciavam aproximadamente 600 metros da Vila. Todas as seis linhas que tangenciavam a Vila seguiam ao Terminal Pinheirinho e a partir deste permitiam o acesso a toda rede de transporte público. Dessa forma, o nível de qualidade foi enquadrado na classe D. No período II, devido às adequações do sistema viário, uma linha de ônibus passou a atender a Vila com três pontos de parada nas vias principais, portanto, essa variável mudou para a classe $\mathrm{A}$.

A categoria de análise Serviços Urbanos, no período I, obteve um IQAU parcial de 55 ficando na classe $\mathrm{C}$, e no período II obteve significativa melhora apresentando um índice máximo de 100, passando para a classe $\mathrm{A}$.

\subsubsection{Infraestrutura social e cultural}

Para analisar a categoria Infraestrutura Social e Cultural, cujos resultados estão demonstrados na Tabela 8, foram elencadas as seguintes variáveis: Saúde, Educação, Lazer e Cultura. Para a variável saúde foi analisada a existência ou não de Unidades Básicas de Saúde para o atendimento do contingente populacional da Vila.

No período I, a comunidade contava com o atendimento de saúde em uma Unidade Básica de Saúde denominada Pompéia. Esta unidade estava dimensionada para atender 12.000 pessoas dos conjuntos habitacionais de sua área de abrangência. Mas de acordo com os dados levantados pela COHAB-CT (2008), a unidade estava sobrecarregada com o cadastro de 14.397 moradores. Dessa forma, o acesso estava comprometido e a categoria 
foi enquadrado na classe $\mathrm{C}$.

No período II, a unidade passou por reforma para ampliação da área física e aumento no número de equipes com médicos, dentistas e enfermeiros, para combater o déficit de atendimento em saúde. Por este motivo e pelo fato de ter tido relocação de parte das residências para outro assentamento, o indicador passou para a classe A. tado se deu pelo fato de ter ocorrido a relocação das 479 famílias para o loteamento Moradias Laguna, desta forma, as escolas da região deixaram de estar sobrecarregadas atendendo à demanda da Vila Terra Santa, se inserindo na classe A.

Quanto a variável lazer e cultura, no período I as famílias da Vila vivenciavam privação em relação ao acesso ao lazer e à cultura, pois o local não pos-

TABELA 8 - Resultados dos indicadores, classe e IQAU parcial na categoria Infraestrutura Social e Cultural para os dois períodos analisados.

\begin{tabular}{|c|c|c|c|c|c|c|}
\hline \multirow[b]{2}{*}{ CATEGORIA } & \multirow[b]{2}{*}{ VARIÁVEL } & \multicolumn{2}{|c|}{ Período I (2000 a 2007) } & \multicolumn{3}{|c|}{ Período II (2008 a 2013) } \\
\hline & & $\begin{array}{c}\text { Médias Pon- } \\
\text { deradas } \\
\text { Indicadores }\end{array}$ & $\begin{array}{l}\text { IQAU } \\
\text { P a r - } \\
\text { cial }\end{array}$ & $\begin{array}{c}\text { Médias Pon- } \\
\text { deradas } \\
\text { indicadores }\end{array}$ & $\begin{array}{l}\text { Classe de } \\
\text { Qualidade }\end{array}$ & $\begin{array}{l}\text { I Q A U } \\
\text { Parcial }\end{array}$ \\
\hline \multirow{4}{*}{$\begin{array}{l}\text { INFRAESTRU- } \\
\text {-TURA SOCIAL E } \\
\text { CULTURAL }\end{array}$} & Saúde & 50 & \multirow{4}{*}{44,08} & 100 & A & \multirow{4}{*}{95,39} \\
\hline & Educação & 62,5 & & 87,5 & A & \\
\hline & Lazer & 0 & & 100 & A & \\
\hline & Cultura & 0 & & 100 & A & \\
\hline
\end{tabular}

FONTE: Autoria própria.

Quanto ao acesso à educação, foi considerada como necessidade primordial o acesso ao ensino infantil, ao ensino fundamental de $1^{\circ}$ ao $5^{\circ}$ e $6^{\circ}$ ao $9^{\circ}$ ano, e ao ensino médio. Segundo os dados levantados no período I, a comunidade tinha à disposição dois Centros Comunitários de Educação Infantil que atendiam parcialmente as crianças da Vila. Como $77,5 \%$ de mulheres eram chefes de família e responsáveis pela moradia, a necessidade de creches era uma das maiores dificuldades enfrentadas pela comunidade. Foi identificado que existia escola municipal e estadual atendendo do Ensino Fundamental ao Ensino Médio. Porém, essas escolas não possuíam vagas para atender a demanda total. Dessa forma, a variável educação ocupava a classe B.

No período II, houve uma melhora na variável educação chegando a um índice de 87,5. Este resul- suía áreas de lazer e convivência, portanto, o nível de enquadramento foi classe E.

Para a variável lazer, no período II foram restauradas as faixas de preservação permanente, que receberam reposição vegetal e a implantação de equipamentos de lazer e recreação. Assim essas áreas adquiriram uma importância no seu processo de socialização, convivência e integração com os equipamentos de lazer implantados como quadras poliesportivas de areia, playgrounds, ciclovias, canchas de bocha e pistas de skate. Segundo relatório da COHAB-CT (2008), esses equipamentos estão localizados num trecho onde a topografia é plana e a canalização do córrego deveria criar uma área contínua que funcionaria como um eixo de convivência e preservação.

Para a variável cultura, no período II foi im- 
plantada a Casa da Comunidade Terra Santa, na qual são desenvolvidas ações culturais sob responsabilidade da Fundação Cultural de Curitiba - FCC. Nesse local ocorreu à inclusão das famílias nos Programas Sociais da Fundação de Ação Social FAS, de modo a ofertar opções de capacitação à comunidade. As variáveis lazer e cultura passaram a ocupar a classe A.

O IQAU parcial da categoria Infraestrutura Social e Cultural era considerado nível classe C, no período I, e no período II passou para classe A.

\subsubsection{Conforto do ambiente e paisagem urbana}

Em relação à categoria de análise Conforto do Ambiente, indicada na Tabela 9, a qualidade visual do corpo hídrico e das nascentes é o que estabelece esta relação. Considerou-se o não lançamento de efluentes e resíduos sólidos nos corpos hídricos como indicador positivo, classificando em existência $(0 \%)$ ou não desta prática $(100 \%)$.
No período I, a categoria Conforto do Ambiente ficou com classe E devido a destinação final dos efluentes. O lançamento "in natura" se dava pela ausência de rede coletora de esgoto na região, que comprometia a qualidade da água do rio Arroio do Pulo, afluente do Rio Barigui - que é um dos principais rios em Curitiba.

No período II, o Conforto do Ambiente em relação à qualidade da água dos rios não melhorou, mesmo após a conclusão das obras de saneamento, pois a cultura de disposição inadequada dos resíduos sólidos ao longo dos rios ainda persiste. Este fato foi identificado durante as visitas técnicas realizadas no assentamento em 2013. Desta forma a variável água (corpo hídrico) continuou como classe E.

Para a categoria de análise Paisagem Urbana, tem-se as variáveis arborização, sinalização e áreas verdes. A arborização viária foi quantificada em metro linear em relação ao total da extensão linear das vias do loteamento, enquanto a sinalização foi avaliada em função da existência de sinais verticais de trânsito.

No período I, em decorrência da antiga preca-

TABELA 9 - Resultados dos indicadores, classe e IQAU parcial na categoria Paisagem Urbana e Conforto do Ambiente para os dois períodos analisados.

\begin{tabular}{|c|c|c|c|c|c|c|c|}
\hline CATEGORIA & VARIÁVEL & \multicolumn{3}{|c|}{ Período I (2000 a 2007) } & \multicolumn{3}{|c|}{ Período II (2008 a 2013) } \\
\hline $\begin{array}{c}\text { CONFORTO DO } \\
\text { AMBIENTE }\end{array}$ & Água (corpo hídrico) & 0 & $\mathrm{E}$ & 0 & 0 & $\mathrm{E}$ & 0 \\
\hline $\begin{array}{c}\text { PAISAGEM UR- } \\
\text { BANA }\end{array}$ & Áreas verdes & 100 & A & & 100 & A & \\
\hline
\end{tabular}

FONTE: Autoria própria. 
riedade ou praticamente inexistência de sistema viário e delimitação urbanística, inexistia qualquer tipo de arborização viária e sinalização, ficando na classe E. No período II, a Prefeitura realizou o plantio de árvores de diversas espécies em 54,47\% de trechos de rua, e instalou sinalização vertical em todas as vias, sendo que a variável arborização passou a enquadrar a classe $\mathrm{C}$, enquanto que a variável sinalização a classe A.

Para a variável áreas verdes, a região na qual se insere a Vila, mesmo tendo sofrido com as mudanças na paisagem devido à remoção da cobertura vegetal no período I, ainda contava com alta densidade de áreas verdes $\left(54,38 \mathrm{~m}^{2} / \mathrm{hab}\right.$.) no bairro Tatuquara, por este ainda apresentar grandes vazios urbanos. A densidade de áreas verdes, mesmo com a ocupação irregular, continuou alta segundo dados nacionais como Brasil (2002), e regionais como IPPUC (2009), e o indicador demonstrou que a Vila se insere na classe A tanto no período I quanto no II.

\subsubsection{Cidadania}

Para a categoria Cidadania, a variável segurança pública foi analisada em relação à taxa de homicídios no bairro Tatuquara, comparando com a taxa de homicídios no mesmo ano ao da Capital.
A presença de bancas de revistas e grupos organizados também foram avaliadas, pois garantem acesso à informação e a organização popular, munindo a população de informação sobre seus direitos e deveres, o que permite com que se tornem agentes transformadores do ambiente. Os resultados dessa categoria estão representados na Tabela 10.

Para a variável segurança pública foi identificado que no bairro Tatuquara a taxa de homicídios, entre os anos de 1998 a 2003, foi de 56 homicídios para cada 100 mil habitantes e foi utilizada para interpretar a situação para o período I desta pesquisa.

A ocorrência de homicídios no bairro doo Tatuquara é muito superior ao valor médio registrado em toda a cidade de Curitiba, que no mesmo período foi de 26,2 homicídios para cada $100 \mathrm{mil}$ habitantes. Segundo o IPPUC (2008), em áreas de ocupação irregular, em geral, as famílias ficam mais vulneráveis pela falta de recursos, portanto, o contato com a criminalidade, a violência doméstica e a estigmatização negativa atingem com maior impacto essas famílias.

No período II, os índices de criminalidade não diminuíram na Vila, assim como também não diminuíram em Curitiba. Segundo Santos (2012), as taxas de homicídios aumentaram para 61,41 homicídios para cada 100 mil habitantes e 45,5 homi-

TABELA 10 - Resultados dos indicadores, classe e IQAU parcial na categoria Cidadania para os dois períodos analisados.

\begin{tabular}{|c|c|c|c|c|c|c|c|}
\hline CATEGORIA & VARIÁVEL & \multicolumn{3}{|c|}{ Período I (2000 a 2007) } & \multicolumn{3}{|c|}{ Período II (2008 a 2013) } \\
\hline \multirow[b]{2}{*}{ CIDADANIA } & Segurança pública & 0 & $\mathrm{E}$ & & 0 & $\mathrm{E}$ & \\
\hline & Informação & 100 & A & 70,37 & 100 & A & 70,37 \\
\hline
\end{tabular}

FONTE: Autoria própria. 
cídios para cada 100 mil habitantes respectivamente. A Vila ainda é um local considerado de alta criminalidade portanto, para esta variável a classe ficou como $\mathrm{E}$ para os dois períodos.

A variável informação indicou que os moradores da Vila Terra Santa tinham no período I à disposição o acesso a informação devido à presença de bancas de jornal e revistas nas intermediações. No período II, a Vila continuou tendo acesso a informação, formando com isso um canal que possibilita cada morador acessar informação e conhecimentos dos seus direitos como cidadão, se assim o quiser.

Em relação à organização popular, em 1999 uma primeira associação de moradores foi constituída juridicamente com o objetivo de representá-los frente às negociações com Órgãos Públicos e proprietários. Segundo relatório da COHAB-CT (2005), em 2001, com a ajuda da Federação Comunitária das Associações de Moradores de Curitiba e Região Metropolitana (FEMOCLAM), a associação de moradores foi dividida em duas para melhor atender e representar as necessidades da comunidade.

Segundo a COHAB-CT (2008), a organização comunitária da Vila Terra Santa, após o início do processo de intervenção, passou a ser representada por três associações de moradores, o objetivo principal destas três organizações era a defesa de direitos dos moradores. Dessa forma, tanto a variável informação, quanto organização popular foram interpretadas como classe A para os dois períodos analisados.

\section{3. Índice de Qualidade Ambiental Urbana - IQAU}

Por meio dos resultados obtidos pela metodo- logia QAU e aplicação de seus indicadores, foi possível desenvolver o Índice de Qualidade Ambiental Urbana final - IQAU final, objetivo desta pesquisa, verificando a sua viabilidade comparando os dois períodos avaliados em um processo espaço-temporal. O resultado da comparação entre os IQAU finais pode ser visualizado na Figura 2.

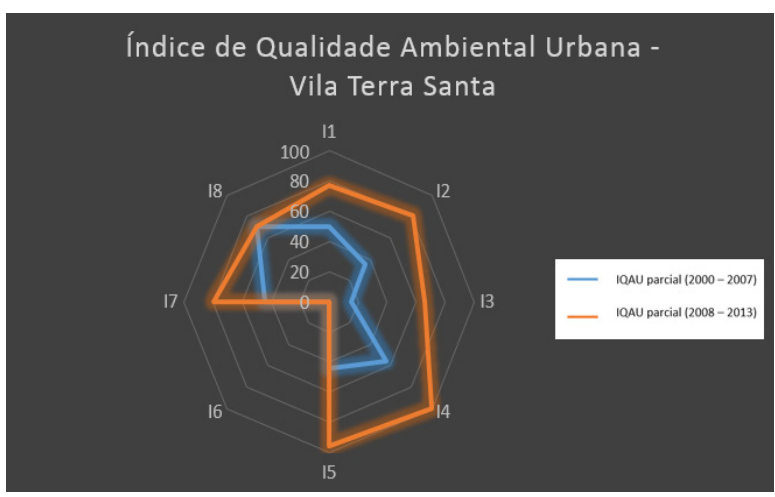

FIGURA 2 - Índice de Qualidade Ambiental Urbana - IQAU da Vila Terra Santa.

FONTE: Autoria Própria.

Legenda: I1 - Índice parcial de Moradia; I2 - Índice parcial de Saneamento; I3 - Índice parcial de infraestrutura urbana; I4 - Índice parcial de Serviços Urbanos; I5 - Índice parcial de infraestrutura social e cultural; I6 - Índice parcial de Conforto Ambiental; I7 - Índice parcial de Paisagem Urbana; I8 - Índice parcial de Cidadania.

A partir da Figura 2 verifica-se que as categorias de análise Serviços Urbanos e Cidadania atingiram o nível de qualidade satisfatório, os demais ficaram abaixo desse nível. Para o período I, o IQAU final se enquadrou na classe D (40,24 média ponderada de todas as categorias analisadas), isto é, insatisfatório. $\mathrm{O}$ resultado demonstra que o intenso processo de ocupação, com suas concepções de uso e transformação do espaço e a divisão da terra de forma não planejada pela comunidade, não beneficia nem a qualidade de vida das pessoas que ali vivem, assim como degrada a qualidade ambiental do local e seu entorno. 
A análise dos indicadores, ao longo do período II, apontaram o IQAU na classe B (72,98 média ponderada de todas as categorias analisadas), considerado como o nível de qualidade muito satisfatório. $\mathrm{O}$ valor do índice muito satisfatório comprova que as ações da regularização promoveram uma evolução tanto na qualidade do ambiente quanto no de infraestrutura e que as mesmas refletiram na melhoria da vida dessa comunidade. Este resultado demonstra que a aplicação de IQUA podem demonstrar de forma coerente as condições avaliadas.

Nesta pesquisa foram adicionadas 3 (três) variáveis, enquanto outras 10 foram retiradas quando comparadas a metodologia original de Borja (1998). Ao todo foram avaliadas 8 (oito) categorias de análise, 34 variáveis para as quais foram aplicados 43 indicadores, dos quais 15 foram adaptados da metodologia original de Borja (1998).

Por meio desta adaptação da metodologia, foi possível analisar e avaliar quantitativamente as 8 (oito) categorias de análise e seus índices, e a inclusão das gradações nos valores dos níveis de classes puderam auxiliar na rápida visualização das melhorias obtidas durante as intervenções realizadas no estudo de caso. O resultado demonstra que 6 (seis) categorias obtiveram melhorias: Moradia, que passou da classe C para B; Saneamento, que passou da D para A; Infraestrutura Urbana, de E para B; Serviços Urbanos, de C para A; Infraestrutura Social e Cultural, de C para A; e Paisagem Urbana, de $\mathrm{C}$ para $\mathrm{B}$. A categoria de análise Conforto do Ambiente e Cidadania permaneceram inalteradas nos dois períodos. Portanto, das 34 variáveis, 22 obtiveram melhora, isto é, aproximadamente $65 \%$ das variáveis mudaram de classe de qualidade após a intervenção e regularização da área, e 12 permaneceram sem alterações, sendo que destas, 9 (nove) já estavam superiores ao nível de qualidade satisfatório.

Cavalcanti et al. (2017), consideram que a influência do planejamento urbano vai causar uma mudança da paisagem e do comportamento social, e que essas mudanças também podem atuar como catalisadores de mudanças mais profundas em direção à sustentabilidade. Assim como Cavalcanti et al. (2017) quanto Tanguay et al. (2010), indicam que o método de avaliação de sustentabilidade poderia ser empregado para a construção de ferramentas de avaliação para outros projetos de infraestrutura portanto, esta metodologia apresentada no artigo visa contribuir nesse sentido, e os mesmos autores indicam que a adoção de métodos de avaliação de sustentabilidade por instituições financeiras e gestores públicos deveria ser altamente recomendada, para que possam contribuir para o desenvolvimento sustentável.

\section{Conclusão}

Nesse trabalho foi realizada uma adaptação da metodologia de Borja (1998), que considera os aspectos socioambientais e de infraestrutura como indicadores voltados para avaliar a Qualidade Ambiental Urbana (QAU).

O estudo de caso, Vila Terra Santa, Curitiba-PR, possibilitou aplicar a metodologia levantando dados dos Períodos I e II - respectivamente anterior e posterior à regularização fundiária, o que permitiu analisar e refletir sobre possíveis adaptações para a mesma. A comparação dos resultados obtidos nos dois períodos, permitiu verificar a viabilidade de aplicar índices parciais e finais na metodologia QAU. 
A utilização de um sistema de índices, como o IQAU, resultou em um formato mais objetivo de demonstrar as mudanças ocorridas, facilitando deste modo a interpretação e avaliação das ações desenvolvidas pela COHAB-CT, o que evidenciou que os IQAU parcial e final podem se constituir em uma ferramenta eficaz e relativamente rápida para interpretar o retrato das intervenções ocorridas. Como a maioria dos dados foram retirados de sites oficiais de instituições que disponibilizam os mesmos, esta aplicação se mostrou ainda mais interessante, por considerar dados de fácil acesso.

Para refinar ainda mais a metodologia aqui proposta, sugere-se a aplicação desta em outros estudos de caso em áreas de regularização fundiária urbana, a fim de verificar a robustez dos indicadores, assim como reestruturá-los, caso se verifique esta necessidade. Sugere-se ainda uma análise mais aprofundada em relação aos valores que foram inseridos nesta pesquisa, pois os mesmos foram atribuídos com o mesmo valor indicados por Borja (1998), porém os indicadores adaptados tiveram seus valores inseridos sem uma discussão entre um maior número de pares. Para pesquisas futuras seria interessante identificar com maior precisão a valoração dos pesos estabelecidos para os indicadores. Esta Metodologia que foi adaptada e aplicada em estudo de caso possui um grande potencial para contribuir na avaliação tanto dos planos Diretores de Cidades quanto dos planos de Bacias Hidrográficas, assim como ser inserida no rol dos Indicadores de Desenvolvimento Sustentável.

\section{Referências}

Abiko, A.; Coelho, L. de O. Urbanização de favelas: procedimentos de gestão. Porto Alegre: ANTAC, 2009 (Recomendações Técnicas, 4). Porto Alegre, 2009.

Brasil. Resolução Conjunta IBAMA/FATIMA n ${ }^{\circ}$ 01, de 05 de abril de 1995. Santa Catarina: AC, 2002.

Borja, P. C. Metodologia para Avaliação da Qualidade Ambiental Urbana em nível local. In: Anais do Congresso Interamericano de Engenharia Sanitária e Ambiental- AIDIS. Lima, Peru, 1998.

Cavalcanti, C. de O.; Limont, M.; Dziedzicb, M.; Fernandes, V. Sustainability assessment methodology of urban mobility projects. Land Use Policy, 60, 334 -342, 2017.

COHAB-CT. Programa Habitar Brasil - BID: Terra Santa Levantamento Aerofotogramétrico. Curitiba: COHAB-CT, 2002. 1 fotografia área. Escala variada.

COHAB-CT - Companhia de Habitação Popular de Curitiba. Programa Habitar Brasil: Projeto Integrado Terra Santa. Diagnóstico - 2005. Curitiba: COHAB-CT, 2005.

COHAB-CT. Projeto de Trabalho Técnico Social: Terra Santa - Moradias Laguna. Curitiba: COHAB-CT, 2008.

CONAMA - Conselho Nacional do Meio Ambiente. Resolução $n^{\circ} 369$, de 28 de março de 2006. Brasília: DOU de 29/03/2006.

Ermínia, M. Metrópole, legislação e desigualdade. Estudos Avançados, 17(48), 2003. Disponível em: http://www. revistas.usp.br/eav/article/view/9928.

Grostein, M. D. Metrópole e expansão urbana: a persistência de processos “insustentáveis”. São Paulo em Perspectiva, 15(1), 13-19, 2001.

Google Maps. Endereço: Vila terra Santa, Tatuquara, Curitiba. Disponível em: https://www.google.com.br/maps/@$-25.5571155,-49.3201092,1386 \mathrm{~m} /$ data $=! 3 \mathrm{~m} 1$ ! $1 \mathrm{e} 3$.

Hladczuk, A. M.; Barz, E. L.; Sutil, M. S.; Boschilia, R. História de Curitiba. Curitiba: Fundação Cultural de Curitiba, 2000. Disponível em: http://www.casadamemoria.org. br/index_historiadecuritiba.html.

IBGE - Instituto Brasileiro de Geografia e Estatística. Censo Demográfico 2010 - Aglomerados Subnormais - Informações Territoriais. Rio de Janeiro: Censo Demográfico, 2010. 
IPPUC - Instituto de Pesquisa e Planejamento Urbano de Curitiba. Plano Municipal de Regularização Fundiária em Áreas de Preservação Permanente. Curitiba: IPPUC, 2007. Disponível em: http://www.concidades.pr.gov.br/arquivos/ File/DOC_IPPUC_Habitacao_Regul_Fund_APP_final.pdf.

IPPUC. Plano Municipal de Habitação e Habitação de Interesse Social. Curitiba: IPPUC, 2008. Disponível em: http://www.ippuc.org.br/ippucweb/sasi/home/.

IPPUC. Curitiba em Dados - 2009. Coord. De Lourival Peyerl. Curitiba: IPPUC, 2009.

Paraná. Companhia de Saneamento do Paraná. Coordenadoria da Unidade de Serviços de Desenvolvimento Operacional. Manual de Projetos Hidrossanitários: roteiro para apresentação de projeto hidrossanitário. Paraná, 2010. Disponível em: http://site.sanepar.com.br/categoria/informacoes-tecnicas/mphs-manual-de-projetos-hidrossanitarios.
Pianucci, M. N. Análise da acessibilidade do sistema de transporte público urbano: estudo de caso na cidade de São Carlos - SP. São Paulo, Dissertação (Mestrado em Engenharia de Transportes e Área de Concentração em Infraestrutura de Transporte) - USP, 2011.

Rolnik, R. A construção de uma política fundiária e de planejamento urbano para o país - avanços e desafios. Políticas Sociais - acompanhamento e análise, 12, 2006. Disponível em: http://www.ipea.gov.br/portal/images/stories/PDFs/ politicas_sociais/ensaio1_raquel12.pdf.

Santos, M. PM lança operação de congelamento para instalação da UPS Ludovica, no Bairro Tatuquara. Policiamento da Capital. Polícia Militar do Paraná, 2012. Disponível em: http://www.policiamilitar.pr.gov.br/modules/noticias/ article.php?storyid=5707.

Tanguay, G. A.; Rajaonson, J.; Lefebvre, J.; Lanoie, P. Measuring the sustainability of cities: An analysis of the use of local indicators. Ecological Indicators, 10(2), 407$418,2010$. 